\title{
Glucocorticosteroid dependent decrease in the activity of calcineurin in the peripheral blood mononuclear cells of patients with systemic lupus erythematosus
}

S Sipka, K Szucs, S Szántó, I Kovács, G Lakos, E Kiss, P Antal-Szalmás, G Szegedi, P Gergely

Abstract

Objective-To compare the activity of calcineurin in the peripheral blood mononuclear cells (PBMC) of 32 patients with systemic lupus erythematosus (SLE) and 35 healthy controls.

Methods-The activity of calcineurin was Methods-The activity of calcineurin was mononuclear cells.

Results-There was no significant difference in the calcineurin activity of patients with SLE not taking glucocorticosteroids (GCS) compared with the healthy controls. On the other hand, the activity of calcineurin was reduced in patients with SLE taking GCS, correlating negatively with the dose of GCS. The stimulation of PBMC by phorbol ester and calcium ionophore decreased the calcineurin activity both in patients with SLE and in healthy controls. GCS could also reduce calcineurin activity in the mononuclear cells of healthy subjects in vitro. cells of healthy subjects in vitro.
Conclusions-In patients with SLE the decrease in the calcineurin activity of PBMC depended on the dose of GCS used for treatment, and it was not a disease specific alteration. The higher the dose of GCS, the greater the inhibition of calcineurin activity. The reduction of calcineurin activity. The reduction of cal-
cineurin activity is a new element in the immunosuppressive effects of GCS during the treatment of patients with SLE.

(Ann Rheum Dis 2001;60:380-384) University of

Debrecen, Hungary

S Sipka,

S Szantó

I Kovács

E Kiss

P Antal-Szalmás

G Szegedi

Department of Medical Chemistry Faculty of Medicine University of Debrecen, Hungary K Szucs

P Gergely

Correspondence to:

Dr S Sipka, 3rd Department of Internal Medicine, Faculty Debrecen, H-4004 Debrecen, Hungary sipka@iiibel.dote.hu

Accepted 22 August 2000
Calcineurin is a $\mathrm{Ca}^{2+} /$ calmodulin dependent protein phosphatase, decreasing the level of phosphorylation in the transcriptional factor
NF-AT (nuclear factor of activated $\mathrm{T}$ cells) required for the production of a series of cytokines (interleukin 2 (IL2), IL4, etc), cell surface molecules (CD40, ICAM, etc), and Fas ligand. ${ }^{15} 16$

In this study we show that in patients with SLE not taking any glucocorticosteroids SLE not taking any glucocorticosteroids
(GCS) the calcineurin activity of peripheral (GCS) the calcineurin activity of peripheral
blood mononuclear cells (PBMC) does not blood mononuclear cells (PBMC) does not
differ from that of healthy controls. On the other hand, in patients with SLE taking various doses of GCS, decreased calcineurin activity can be measured. The higher the concentration of GCS, the greater the decrease in calcineurin che the CC by phorbol ester and $\mathrm{Ca}^{2+}$ ionophore (A23187) results in a pronounced decrease in the calcineurin activity of cells derived from patients with SLE or from healthy controls. GCS can reduce the calcineurin activity also in the mononuclear cells of healthy subjects in vitro.

\section{Patients and methods}

PATIENTS, CLINICAL DATA, AND CONTROL GROUP The SLE study group comprised 32 patients, 29 women and three men, with a median age of 36 years (range 18-68). The mean SLE disease activity index (SLEDAI) was 4.1 (range 2-20). The average dose of GCS (methylprednisolone or equivalent of prednisolone) taken by the patients was $9.8 \mathrm{mg} /$ day (range $0-32$ ). These patients were free from any cytostatic drug. The average duration of the disease was 8.5 years (range 0.5-35). Three subgroups of these patients were studied: $(a)$ seven patients patients were studied: (a) seven pats, (six SLEDA 2.43; (b) six patients (five women, one man) taking $8 \mathrm{mg}$ of GCS/day, median age 39 year (range 18-55), mean SLEDAI 4.4; (c) six patients (five women, one man) taking $32 \mathrm{mg}$ of GCS/day, median age 43 years (range 19-52), mean SLEDAI 11.5 Thirty five healthy white subjects (32 women, three men), median age 36 years (range $20-52$ ), served as controls. Approval was given through the institutional review board, and informed consent was obtained from all participants. All patients with SLE fulfilled the diagnostic criteria of the American College of Rheumatology with at least four of the revised criteria for the diagnosis of $\mathrm{SLE}^{17}$ Patients with a SLEE were considered to have inactive disease ${ }^{18}$ 


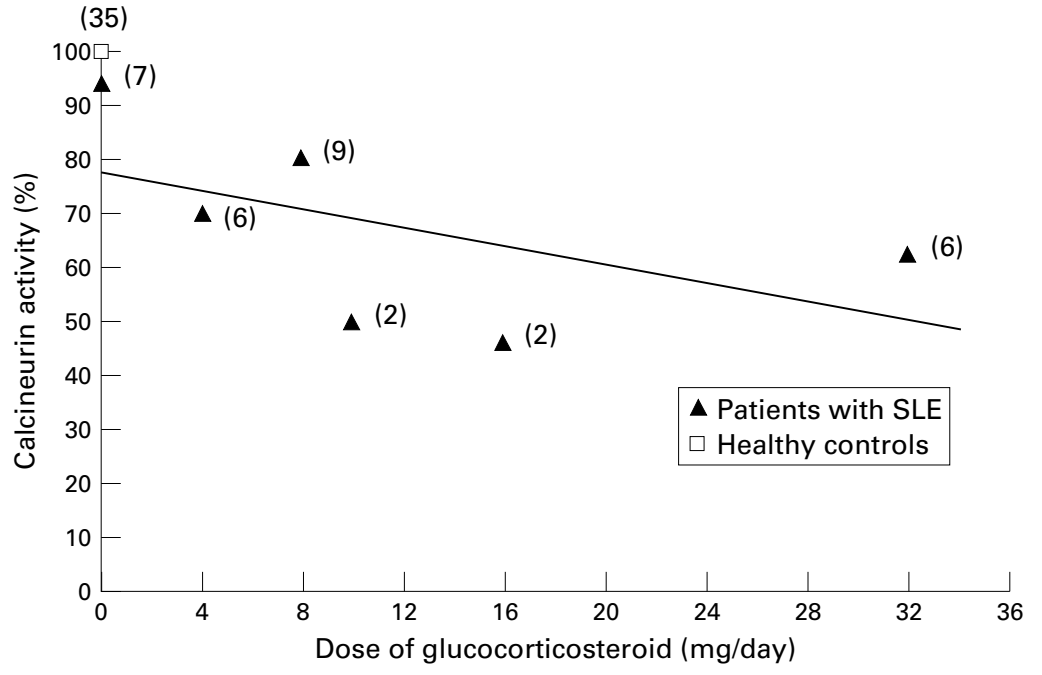

Figure 1 Negative correlation between the basal activities of calcineurin in the peripheral
blood mononuclear cells (PBMC) of patients with systemic lupus erythematosus (SLE) and the doses of glucocorticosteroids (GCS) used for treatment. The coefficient of correlation between the basal calcineurin activities in the PBMC and the daily doses of GCS (0-32 ing/day) taken by patients with SLE was calculated. The calcineurin activity

PREPARATION OF HUMAN MONONUCLEAR CELLS AND CHARACTERISATION BY FLOW CYTOMETRY Human PBMC with an average of $88-95 \%$ lymphocytes and $5-12 \%$ monocytes were prepared from heparinised blood of patients with
SLE and controls according to Boyum's SLE and controls according to Boyum's method. ${ }^{19}$ The averages of the various subsets were detected by flow cytometry: CD3+ $69.4 \%, \mathrm{CD} 19+10.5 \%, \mathrm{CD} 56+1.8 \%$, and CD14+ $8.3 \%$. The suspensions of mononuclear cells $\left(10^{6}\right.$ cells per sample) were labelled by saturating concentrations of anti-CD3FITC (T3, Coulter, Hialeah, USA), antiCD19-RD1 (B4, Coulter), anti-CD56-PE (Leu-19, Becton-Dickinson, Mountain View, USA), and anti-CD14-RD1 (MY4, Coulter). After staining and fixing, the cells were analysed by a Coulter EPICS XL flow cytometer (Coulter, USA)

STIMULATION OF PBMC BY PHORBOL ESTER AND CALCIUM IONOPHORE

Phorbol ester (PMA, phorbol-12-myristate-13 acetate, Sigma, St Louis, USA) $50 \mathrm{ng} / \mathrm{ml}$ and 5 umol/1 calcium ionophore (A23187, Sigma USA) were added to the cells at $37^{\circ} \mathrm{C}$ for four hours.

MEASUREMENT OF CALCINEURIN ACTIVITY

Cell suspensions were washed with phosphate buffered saline and collected by centrifugation. Cells were sonicated for $2 \times 30$ seconds with a Branson sonifier in two volumes of homogenisation buffer containing $50 \mathrm{mM}$ Tris- $\mathrm{HCl}(\mathrm{pH}$ 7.0), $0.5 \mathrm{M}$ dithiothreitol, $10 \mu \mathrm{g} / \mathrm{ml}$ aprotinin, $10 \mu \mathrm{g} / \mathrm{ml}$ leupeptin, $10 \mu \mathrm{g} / \mathrm{ml}$ trypsin inhibitor, $1 \mathrm{mM}$ phenylmethylsulphonyl fluoride (PMSF), $5 \mathrm{mM}$ benzamidine, and $0.3 \%$ Triton $\mathrm{X}-100$. The homogenate was centrifuged for 10 minutes at $10000 \mathrm{~g}$, and supernatants were collected and stored in aliquots at $-70^{\circ} \mathrm{C}$ before the assays.

Calcineurin activity was measured by the release of ${ }^{32} \mathrm{P}$ from ${ }^{32} \mathrm{P}$ labelled protein phosphatase inhibitor $1^{20}$ as described by Yang et $a l^{11}$ with slight modifications. The assay mixture $(30 \mu \mathrm{l})$ containing $50 \mathrm{mM}$ Tris- $\mathrm{HCl}(\mathrm{pH}$ 7.0), $0.3 \mathrm{mM}$ dithiothreitol, $0.2 \mathrm{mM} \mathrm{CaCl}$ $1 \mathrm{mM} \mathrm{MnCl}, 0.04 \mathrm{mg} / \mathrm{ml}$ calmodulin or 2 EGTA, an appropriate amount of ex (0.5-1.5 $\mathrm{mg} / \mathrm{ml}$ proprin), and ${ }^{32} \mathrm{P}$ labelled protein phosphatase inhibitor 1 (12-25000 $\mathrm{cpm} /$ reaction mixture) was incubated at $30^{\circ} \mathrm{C}$ for 10 minutes. All mixtures contained 10 $\mu \mathrm{g} / \mathrm{ml}$ aprotinin, $10 \mu \mathrm{g} / \mathrm{ml}$ leupeptin, $10 \mu \mathrm{g} / \mathrm{ml}$ trypsin inhibitor, $1 \mathrm{mM}$ PMSF, $5 \mathrm{mM}$ benzamidine as protease inhibitors, and $20 \mathrm{nM}$ inic und protein phosphatase was not assayed under the conditions give above, because $200 \mathrm{nM}$ of okadaic acid did no result in any inhibition. The reaction was terminated by the addition of $100 \mu \mathrm{l}$ of $10 \%$ trichloroacetic acid. ${ }^{32} \mathrm{P}_{\mathrm{i}}$ of the supernatant fraction was determined after centrifugation by Cerenkov counting in a liquid scintillation uid scintillation counter. The activity of calcineurin was calculated as the difference between ${ }^{32} \mathrm{P}_{\mathrm{i}}$ counts in
the absence and presence of $\mathrm{Mn}^{2+} / \mathrm{Ca}^{2+} /$ calmodulin.

CULTURING OF PBMC IN THE PRESENCE OF PREDNISOLONE SODIUM SUCCINATE

PBMC of five healthy controls were cultured for 72 hours in the absence and presence of $10^{-4} \mathrm{M}$ prednisolone sodium succinate (Diadreson-FAquosum, Organon, The Netherlands) in RPMI medium with fetal calf serum $(10 \%)$.

STATISTICAL ANALYSIS

Statistical means and SD values were calcuated to compare the activity of calcineurin in the patients with SLE and in the healthy controls. The statistical significance of the difcontrols. The statistical significance of the diftest. During measurements of the in vitro effects of GCS on calcineurin activity, each value was calculated as the mean of the data from five healthy control subjects. In these experiments the statistical significance was calculated by Student's paired $t$ test. The correlation coefficient between the calcineurin activition coefficient between the calcineurin activi-
ties and the doses of GCS was determined in ties and the doses of GCS was determined in
the patients with SLE. In these studies the calcineurin activities of the individual patients were expressed as a percentage of the activities measured in the healthy controls, which were considered to be $100 \%$.

Results

During the first phase of the experiment we compared the activity of calcineurin in the PBMC of patients with SLE and in health controls. As the calcineurin activities obtained from the patients with SLE were diverse, the aily doses of GCS taken by the subjects were considered when the data were analysed.

NEGATIVE CORRELATION BETWEEN THE BASAL ACTIVITIES OF CALCINEURIN IN PBMC OF PATIENTS WITH SLE AND THE DOSES OF GCS USED FOR THE TREATMENT

The correlation between the basal calcineurin activities in the PBMC and the daily doses of GCS $(0-32 \mathrm{mg} /$ day $)$ taken by the 32 patients 


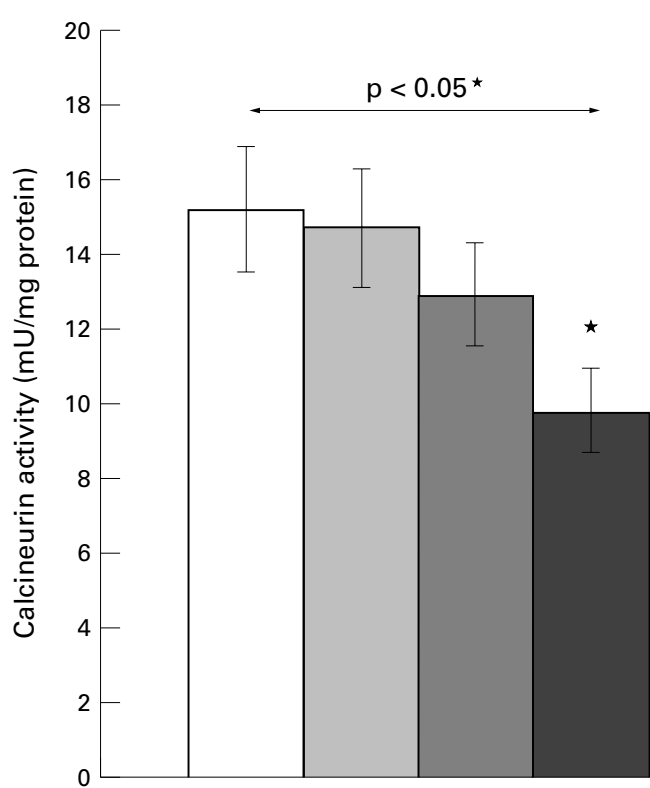

Non-stimulated PBMC

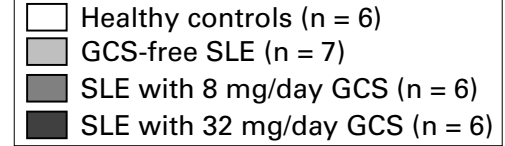

SLE with $8 \mathrm{mg} /$ day GCS $(\mathrm{n}=6)$
SLE with $32 \mathrm{mg} / \mathrm{day}$ GCS $(\mathrm{n}=6)$

Figure 2 Calcineurin activities in the peripheral blood mononuclear cells (PBMC) of patients with systemic lupus . crythematosus (SLE) with or without glucocorticosteroid (GCS) treatment and in healthy controls. Calcineurin activities statistical significance of the differences was calculated by Student's unpaired t test. Asterisk denotes significant difference compared with the controls.

with SLE was calculated. It was found to be highly significant: $r_{\mathrm{s}}=-0.52 \quad(\mathrm{p}<0.001)$. The inhibition of calcineurin activity in the PBMC of patients with SLE may be a new factor in the immunosuppression caused by GCS. There was no significant difference in the calcineurin activities of seven GCS-free patients with SLE and those of 35 healthy controls (fig 1).

CALCINEURIN ACTIVITIES IN THE PBMC OF PATIENTS WITH SLE WITH OR WITHOUT GCS TREATMENT AND IN HEALTHY CONTROLS

In four groups of subjects the calcineurin activities of PBMC were assayed and compared. The cells were either non-stimulated or

stimulated by PMA and $\mathrm{Ca}^{2+}$ ionophore. In the non-stimulated cells of six patients with SLE taking $32 \mathrm{mg}$ of GCS/day, there was ignificant decrease in the calcineurin activity compared with the value of six healthy controls $(9.7 \mathrm{mU} / \mathrm{mg}$ v $15.1 \mathrm{mU} / \mathrm{mg}, \mathrm{p}<0.05)$. In the seven GCS-free patients or in the six patients taking $8 \mathrm{mg}$ of GCS/day, the changes were not significant compared with the values of the healthy controls $(14.6 \mathrm{mU} / \mathrm{mg}$ and 12.8 $\mathrm{mU} / \mathrm{mg} v 15.1 \mathrm{mU} / \mathrm{mg}$ ). In the cells stimulated by PMA and $\mathrm{Ca}^{2+}$ ionophore for four hours there was a marked decrease in the calcineurin activities of all groups compared with their

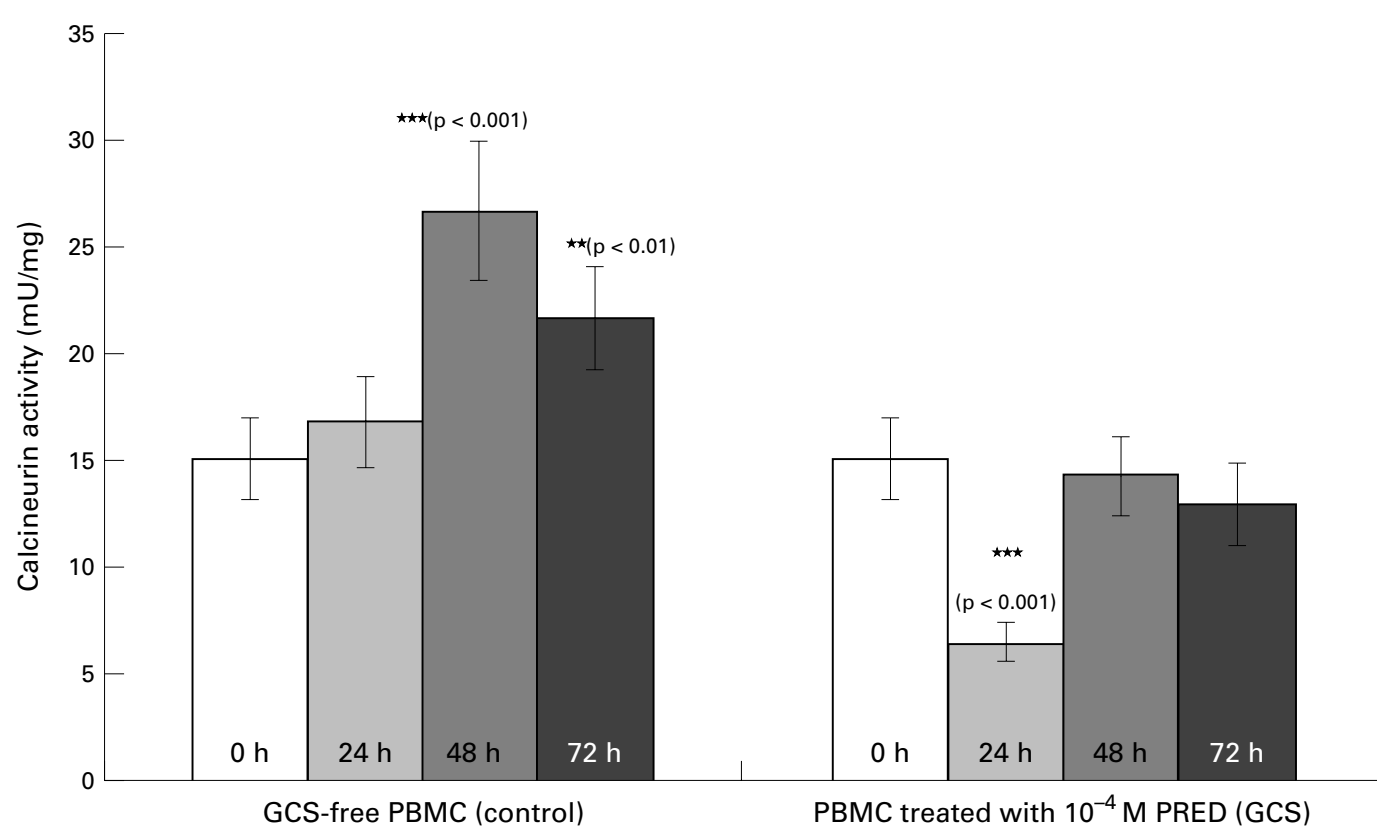

Figure 3 In vitro effect of prednisolone sodium succinate (PRED) on the activity of calcineurin in peripheral blood mononuclear cells (PBMC) of healthy subjects. PBMC of five healthy controls were cultured for 72 hours in the absence and presence of $10^{-4} M$ PRED. Calcineurin activities were determined and the statistical analysis was carried out as described in "Patients and methods". Asterisks denote significant differences compared with the respective controls. For the 
non-stimulated counterparts: 5.2, 4.9, 4.5, and $3.8 \mathrm{mU} / \mathrm{mg} v 15.1,14.6,12.8$, and $9.7 \mathrm{mU} / \mathrm{mg}$ $(\mathrm{p}<0.001)$. The differences between the calcineurin activities of the stimulated cells in the four groups were not significant, but the changes showed a pattern similar to those found in the non-stimulated cells-the highest activity was measured in the healthy controls, the lowest in the patients receiving $32 \mathrm{mg}$ of GCS/day (fig 2). In addition, we found no significant differences in the calcineurin activities of men or women with SLE taking or not taking GCS, but each group contained only one man (data not shown).

IN VITRO EFFECT OF PREDNISOLONE SODIUM SUCCINATE ON THE ACTIVITY OF CALCINEURIN IN PBMC OF HEALTHY SUBJECTS

To verify the inhibitory effect of GCS on calcineurin activity, the mononuclear cells of healthy controls were cultured with or without $10^{-4} \mathrm{M}$ prednisolone sodium succinate (PRED) for 72 hours. This non-toxic dose of the drug had significantly inhibited calcineurin after 24 hours: $16.8 \mathrm{mU} / \mathrm{mg} v 6.4 \mathrm{mU} / \mathrm{mg}$ $(p<0.001)$, whereas a slight but not significant increase of calcineurin activity was seen in the control cells $(15.1 \mathrm{mU} / \mathrm{mg} v 16.8 \mathrm{mU} / \mathrm{mg})$. The activity of calcineurin increased even further in the GCS-free cultures over the next two days: 26.7 and $21.6 \mathrm{mU} / \mathrm{mg}$ at 48 and 72 hours, respectively $(\mathrm{p}<0.001$ and $\mathrm{p}<0.01)$. A similar tendency was seen in the cells treated with PRED. The activity of calcineurin increased significantly from the value at 24 hours $(6.4 \mathrm{mU} / \mathrm{mg})$ to $14.2 \mathrm{mU} / \mathrm{mg}$ and $12.9 \mathrm{mU} / \mathrm{mg}$ at 48 and 72 hour of PRED remained always significantly lower of PRED remained always significantly lower
than those in the GCS-free cultures (fig 3). An assay of lactate dehydrogenase activities in the supernatants of cultured cells showed that neither the culturing nor the presence of PRED caused any cellular damage (data not shown). Thus the decreased calcineurin activity may be related to the effect of PRED.

Discussion

The goal of these experiments was to measure the activity of calcineurin in the PBMC of patients with SLE. The major results are as follows. Firstly, there is no difference in the calcineurin activities of PBMC in the GCS-free patients with SLE and healthy control subjects. Secondly, as far as we know, this is the first experimental evidence of decreased calcineurin activity of PBMC induced by GCS used for the treatment of patients with SLE.

Unfractionated PBMC - that is, suspensions of $\mathrm{T}$ and $\mathrm{B}$ lymphocytes, NK cells, and monocytes, were used in this study because the calcineurin activity assays required a large number of cells. As patients with SLE are lymphopenic it would have been difficult to obtain a sufficient volume of blood for the separation of various purified subsets of the cells. As the subsets of PBMC were characterised by flow cytometry, and as it was found that $69.4 \%$ of the cells were $T$ cells, these preparations could be regarded as "T cell-rich suspensions".
There was no significant difference in the proportions of the various subsets of PBMC in the patients with SLE and the controls.

PRED was chosen for the in vitro experiments because the derivatives of prednisolone were patients with SLE. PRED was judged not toxic in these studies, according to the lactate dehydrogenase measurements. It is known that al GCS have both genomic and non-genomic membrane effects. ${ }^{22}{ }^{23}$ According to these reports, the $32 \mathrm{mg} /$ day dose of GCS in our vitro experiments might have had a significan non-genomic influence, playing a part in the reduction of calcineurin activity. We found no decrease in the amount of calcineurin detected by immunoblotting (data are not shown) either in the cells of patients or in the cells of in vitro experiments treated with high doses of GCS, experiments 列 synthesis of the enzyme. However, in these cells an increased rate of apoptosis was detected a 24 and 48 hours of culturing compared with the GCS-free cells (data are not shown). This observation is in an accordance with an earlier observation that the rate of apoptosis is treated with GCS ${ }^{24}$ Therefore, we suppose that cabin 1, a newly discovered endogenous nhibitor of calcineurin, might possibly be one of the key molecules playing a part in this phenomenon, coupling the processes of steroid receptor regulation, apoptosis, and reduction of calcineurin activity in the $\mathrm{PBMC}^{25-27}$ play a part in calcineurin activity seen in the cells stimulated by phorbol ester and $\mathrm{Ca}^{2+}$ onophore in our experiments. ${ }^{28}$

Our results confirmed the observation of Rider et $a l,{ }^{13}$ who found no difference in the amounts of calcineurin mRNA in patients with SLE and healthy controls. According to our data this similarity was also reflected in the calcineurin activities of the PBMC of patient with SLE and healthy subjects. The significantly deceased calcineurin activity of PBMC measured in patients with SLE treated with 32 $\mathrm{mg}$ GCS/day, however, is a new observation. In addition, a significant negative correlation was found between the doses of GCS used in the This effect of GCS may also be an element of the immunosuppression related to the inhibition of the production of NF-AT dependen cytokines $^{11}$ (for example, IL2, IL4, IL8, and IL13) in patients with SLE, and this pathway may coexist with other, well known influences of $\mathrm{GCS}^{29}$ Calcineurin is a $\mathrm{Ca}^{2+}$ dependent enzyme ${ }^{15}$ and therefore, the inhibition of $\mathrm{Ca}^{2+}$ nflux by $\mathrm{GCS}^{30}$ may have an important role in the GCS dependent decrease of calcineurin activity. This fact may partly explain the earlier finding that GCS inhibit the calcineurin dependent activation of IL2 $2^{31}$ and IL $4^{32}$ genes. However, the inhibition of calcineurin by GCS is not a phenomenon specific to SLE because an be induced also in a dose dependent man- 
The mononuclear cells of healthy controls cultured in vitro showed rather different patterns of calcineurin activity in the untreated and PRED treated series (fig 3). The gradually increasing calcineurin activities of control cultures could be attributed to the production of several cytokines (for example, TNF or IL1) derived from the mononuclear cells attached to the surface of plastic dishes used for the culturing. ${ }^{34}$ By increasing the intracellular levels of $\mathrm{Ca}^{2+}, \mathrm{TNF}$ and IL1 could significantly increase the calcineurin activity of cells cultured for longer than 24 hours. ${ }^{35}$ The significant inhibition of calcineurin seen in the cells cultured in the presence of PRED for 24 hours was described recently. ${ }^{33}$ However, the recovery of calcineurin activity in the PRED treated cells from its reduced level at 24 hours may be explained by the appearance of the cytokines (TNF and IL1) during the second day of culturing (48 hours). As PRED can also inhibit the cytokine production of cultured cells activated by the plastic surface, the calcineurin activity increased by the effect of cytokines could never reach the values seen in the GCSfree counterparts of these cells.

Our data show that the decreased calcineurin activity induced by high doses of GCS may represent a new element in the immunomay represent a new element in the immuno-
suppressive treatment of patients with SLE.

The authors thank Mrs Julia Hunyadi for expert technical

Grants: National Scientific Research Fund (OTKA T023199 try of Health (ETT T-05214/999, 1/2000, 566/2000, H.A.S.
TKI).

1 Tsokos CG, Liossis SNC. Immune cell signaling defects in lupus: activation, energy and death. Immunol Today

Tada Y, Nagasawa K, Yamauchi Y, Tsukamoto H, Niho Y. A defect in the protein kinase $\mathrm{C}$ system in $\mathrm{T}$ cells from
patients with systemic lupus erythematosus. Clin Immunol patients with systemic lupus erythematosus. Clin Immunol
Immunopathol 1991:60:220-31.

3 Laxminarayana D, Khan IU, Mishra N, Olorenshaw I, kinase A RI $\alpha$ and RI $\beta$ transcripts and proteins in system lupus erythe natosus. J Inver kinase A deficiency in systemic lupus erythematosus. Arthritis Rheum 1999;42:1458-65.

CV, Gonzalez-Cabello R, Gergely P. Cyclic AMP level of lymphocytes in patients disease activity. Immunol Lett 1980:23:61-4.

6 Wong HK, Kammer GM, Dennis G, Tsokos GC. Abnormal $T$ lymphocytes from patients with systemic lupus erythematosus is associated with decreased
p65-Rel A protein expression. J Immunol 1999;163: 1682-9.
Lukács K, Kávai M, Sipka S, Sonkoly I, Szabó G, Szegedi Gy. Defective monocyte chemotaxis in systemic lupus ery-
thematosus. Acta Med Acad Sci Hung 1981;38:49-55. (n). Defective monocyte function in patients with systemic lupus
erythematosus. Clin Immunol Immunopathol 1985;34:6976.

9 Vazquez-Doval J, Sanchez-Ibarolla A. Defective mononuetal filaments. J Investig Allergol Clin Immunol 1993;3:8610 Shome GP, Yamane K. Decreased release of leukotriene B4
from monocytes and polymorphonuclear leukocytes in patients with systemic lupus erythematosus. Areguri 1991 Mene P,

Pecci G, Cinotti GA, Pugliese G, Pricci F. Eicosanoid synthesis in peripheral blood monocytes: a marker of
disease activity in lupus nephritis. Am J Kidney Dis $1998 ;$

Gyimesi E, Kavai M, Kiss E, Csipo I, Szucs G, Szegedi Gy Triggering of respiratory burst by phagocytosis in mono-
cytes of patients with systhemic lupus erythematosus. Clin Exp Immunol 1993;94:140-4.

Rider V, Foster R1, Evans M, Suenagy R, Abdou NI. Gencalcineurin expression in systemic lupus erythematosus. Clin Immunol Immunopathol 1998;89:171-80.

Rider V Evans M, Abdou NI. Molecular mech nisms involved in the estrogen-dependent regulation of calImmunol 2000;95:124-34.

15 Guerini D. Calcineurin: not just a simple protein phossive drugs C, Nordheim A. Effects of the immunosuppres-

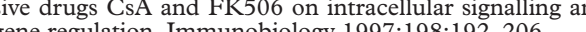
7 Hochberg M. Updating the American College of Rheum tology revised criteria for the clinical classification of
systemic lupus erythematosus. Arthritis Rheum 1997;40:

8 Bombardier C, Gladman D, Urowitz M, Caron D, Chang, and the Committee on Prognosis Studies in SLE. patients. Arthrits Rheum 1992;35:630-40.

Boyum A. Isolation of mononuclear cells and granulocytes
from human blood. J Clin Lab Invest Suppl 1968;97:77Suppl 1968;97:77Cohen P, Foulkes G, Holmes CFB, Nimmo GA, Tonks NK Protein phosphatase inhibitor-1 and inhibitor-2 from
rabbit skeletal muscle. Methods Enzymol 1988;159:427-

1 Yang SD, Tallant AN, Cheung WY. Calcineurin is a phys Res Commun 1982;4:1419-23.

22 Buttgereit F, Brand MD, Burmester GD. Equivalent doses and relative drug potencies for non-genomic glucocorticoid col 1999;58:363-8

23 Lipworth BJ. Therapeutic implications of non-genomic glucocorticoid activity. Lancet 2000;356:87-9.
Seki M, Ushiyama C Seta N, Abe K, Fukazawa T, Asakawa $\mathrm{J}$, et al. Apoptosis of lymphocytes induced by glucocorticosteroids and relationship to therapeutic efficacy in patients
with systemic lupus erythematosus. Arthritis Rheum 1998;

activation protects Ti R, Mukai M, Iwata M. Calcineurin apoptosis. J Immunol 1995;154:6346-54

Pons of $\mathrm{T}$ cells tor MEF2. Science 1999;286:790-3.

7 Youn HD, Grozinger CM, Liu JO. Calcium regulates histon deacetylase $4 \mathrm{~J}$. 8 Sun L, Youn HD, Loh C, Stolow M, He W, Liu JO. Cabin 1 , a negative regulator for calcineurin signaling in Barnes PI. Molecular mechanisms

Barnes PJ. Molecular mechanisms of steroid action in

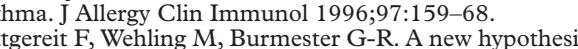
of modular glucocorticoid actions. Arthritis Rheu

Paliogianni F, Boumpas DT. Glucocorticoids regulate
calcineurin dependent transactivating pathways for interleukin-2 gene transcription in human T lymphocytes.

32 Chen R, Burke TF, Cumberland JE, Brummet M, Beck LA Casolaro V, et al. Glucocorticoids inhibit calcium- an calcineurin-dependent activation of human IL-4 promoter.
J Immunol 2000;164:825-32.

3 Sipka S, Szucs K, Szántó S, Kovács I, Lakos G Antal-Szalmás $\mathrm{P}$, et al. Inhibition of calcineurin activity and protection against cyclosporin $\mathrm{A}$ induced cytotoxicity by
prednisolone sodium succinate in human peripheral mononuclear cells. J Immunopharmacol 2000;48:87-92. 4 Bing RJ, Dudek P, Kahler I, Narayan KS, Ingram M. nuclear cells attached to plastic beads. Tissue Cell 2:24:203-9.

Wilkinsone MF, Earle ML, Triggle CR, Barnes PJ.

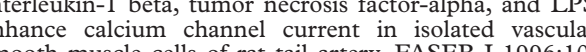
smooth 